OSCE Regarding Clinical Competence and Stressors

\title{
Assessment of Objective Structured Clinical Examination (OSCE) Regarding Clinical Competence and Stressors: Nursing Students' Perspectives
}

Intessar Mohamed Ahmed, Lecturer

Critical care and emergency nursing, Faculty of Nursing, Damanhur University

Lucy Abu El Alla, Lecturer

Nursing Education, Faculty of Nursing, Damanhur University

\begin{abstract}
Background: Clinical education is one of the important and basic principles in nursing education which is accepted by all programmers and managers of educational programs of this field as the main part of nursing education. The assessment of clinical competence is therefore an important issue in nursing education and the utilization of objective structured clinical evaluation (OSCE) for that purpose is considered very important. The skills component in nursing-related subjects contributes to at least $50 \%$ of the content of these subjects, with this high proportion also requiring that any assessment should reflect this significant emphasis on the skills (psychomotor) component. Objective: The aim of this study was to assess objective structured clinical Examination's regarding clinical competence and stressors among undergraduate nursing students. Setting: It was carried out at critical care and emergency nursing department, faculty of nursing, Damanhour University. Subjects: This study involved 85 undergraduate nursing students. Tools: Assessment of Objective Structured Clinical Examination regarding clinical competence and stressors structure questionnaire was used to collect data. The questionnaire consists of 20 statements. 10 statements related to clinical competence and the other related to stressors. For each statement students were asked to rate their responses on a point scale rating from 1-5. (1) For strongly disagree, (2) for disagree, (3) for not sure, (4) for agree and (5) for strongly agree. Results: It was found that the majority of the respondents agreed or strongly agreed that they received enough information, appropriate repetition of OSCE, the quality of information was quiet well, OSCE is a standardized exam for all students, OSCE is a fair exam, OSCE minimizes chances of failing, students prepare differently for OSCE than for other clinical examinations, OSCE provides them with practical and useful experience, OSCE chance for developing confidence
\end{abstract}


OSCE Regarding Clinical Competence and Stressors

to conduct similar procedure on real patients, OSCE scores truly reflect competence in clinical skills, OSCE has a positive impact on clinical learning. Most of the studied sample disagreed or strongly disagreed that level of stress was low, time to complete procedure or reading instructions was enough. Conclusion: Nursing students perceived OSCE as suitable method which improves their clinical competence. But there was time limitation while its implementation and the majority of students considered it as one of the important factors in producing stress in OSCE. Recommendations: Determine time needed for each procedure and accommodate OSCE, and Increase frequencies of OSCE through open lab hour.

\section{Introduction}

Clinical education is one of the important and basic principles in nursing education which is accepted by all programmers and managers of educational programs of this field as the main part of nursing education ${ }^{(1)}$. The nursing profession is characterized by the fact that a significant amount of time is spent on competency-related activities. These competency-related activities are fundamental to the caring role of nurses and are central to the nursing curriculum ${ }^{(2)}$.

Knowledge, attitude and skills form part of this competency component. In addition, assessment is an important part of this process toward competency and it contributes to the ongoing improvement of students' capabilities ${ }^{(3)}$. During this process the student achieves clinical experiences beside the patient while facing problems in the hospital ${ }^{(1)}$. Because of these assessing students' clinical competency of the achieved skills is one of the most difficult tasks of faculty members and health program educator $^{(4)}$.

The assessment of clinical competence is therefore an important issue in nursing education and the utilization of objective structured clinical evaluation (OSCE) for that purpose is considered very important $^{(5)}$. The skills component in nursing-related subjects contributes to at least $50 \%$ of the content of these subjects, with this high proportion also requiring that any assessment should reflect this significant emphasis on the skills (psychomotor) component ${ }^{(6)}$.

According to the fact that evaluation is judgment process about the effectiveness of the individual's educational experiences through appropriate measurement, the method of doing it could improve the quality of teaching, learning, and training ${ }^{(7)}$. During the past 40 years gradual evolution in different methods of clinical evaluation and the appearance of structured objective clinical evaluation as a method of 
assessing clinical competency in medical education is one of them ${ }^{(8)}$.

The course of nursing skills and principles is one of the basic courses in clinical education of nursing students and learning techniques before starting clinical training are of prime importance and students' satisfaction rate with the evaluation method can be effective in creating motivation in their learning. Clinical skills and practice play the main roles in training different groups; the success of trainees of these fields depends on what they memorize to some extent ${ }^{(9)}$. Effective and accurate clinical evaluation should be of concern to all nursing faculties and clinical instructors ${ }^{(10)}$.

There is a reasonable expectation for evaluation to be objective, fair, specific, and documented. In addition, students need to know, very clearly delineated, the specific objectives by which they are being evaluated. One type of assessment which meets these criteria is a performance based assessment. An example of a performancebased assessment is the $\operatorname{OSCE}^{(10)}$. OSCE has been widely and increasingly used since it was developed. Studies have shown that it is an effective evaluation tool to assess practical skills. In many instances the OSCE process has been adapted to test trainees from different healthcare related disciplines $^{(11)}$. In nursing education principles of OSCE can also be used in a formative way to enhance skills acquisition through simulation ${ }^{(12)}$.

Steady increase in number of students enrolled at Egyptian nursing faculties might increase the chances of malpractice that compromise patient"s conditions, in addition to limited resources from clinical sites that might hinder the opportunity of student to practice on patient $^{(13)}$. Nurse teachers carried out the assessment of student performance giving summative scores in traditional assessment method. While in OSCE simulation, the students find learning such skills are more beneficial because there is an immediate formative feedback following an event. Simulation-based training is superior to problem based learning for the acquisition of critical assessment and management skills concluded that OSCEs can be used most effectively in nurse undergraduate curricula to assess safe practice in terms of performance of psychomotor skills, as well as the declarative and schematic knowledge associated with their application $^{(10)}$.

The OSCE can include both summative and formative components, in which a judgment or evaluation of an individual's performance is made (summative) followed by the provision of feedback, from which the student can learn 
(formative). Moreover, during OSCE each student is required to demonstrate specific behaviors in a simulated work environment, strict control over the clinical context is possible, while at the same time, reflecting real-life professional tasks. This control eliminates the lack of the draw 'problem that arises when students are assessed within the real-world 'clinical environment with actual patients as well as the risk of harm occurring to a patient ${ }^{(14)}$.

OSCE is a valuable strategy to assess fitness to practice at the students' expected level of clinical practice within a nursing context where the importance of accurate patient assessment is paramount.

\section{Aim of the Study}

The aim of this study was to assess objective structured clinical examination's regarding clinical competence and stressors as perceived by nursing students.

\section{$\underline{\text { Research Question: }}$}

What is the student's perception about OSCE in relation to their clinical competence and stressors?

\section{Materials and Method}

\section{Materials}

Design: This study has descriptive design.
Setting: The study was carried out at critical care and emergency nursing department, faculty of nursing, Damanhour University.

Subjects: The data collection started at the end of academic year 2013-2014. This study involved 31 students enrolled in emergency nursing course ( $2^{\text {nd }}$ year) and 27 students enrolled in critical care nursing course $\left(3^{\text {rd }}\right.$ year $)$.

Moreover, as it was felt that the students evaluation for OSCE regarding their clinical competence may be changed after one year as a result of the passage of time based on these considerations 27 students nursing enrolled in critical care and emergency nursing during previous academic year 2012-2013 academic years ( $4^{\text {th }}$ year) was involved in this study.

The total number of undergraduate nursing student participated in the study was 85 and all of those students had been assessed by means of OSCE.

\section{$\underline{\text { Tools: }}$}

\section{Tool I: Assessment of Objective} Structured Clinical Examination regarding clinical competence and stressors structure questionnaire was developed and used to collect data. The questionnaire consists of 20 statements. 10 
statements related to clinical competence and the other related to stressors.

For each statement students were asked to rate their responses on a point scale rating from 1-5. (1) For strongly disagree, (2) for disagree, (3) not sure, (4) for agree and (5) for strongly agree.

\section{Method}

Permission to conduct the study was obtained from the Dean of the faculty of nursing. The study was explained to every student and the student's consent was obtained before starting the study.

After reviewing related literature to fulfill the aim of the study, tool was developed by the researchers. The tool was tested by 5 experts in education nursing field and critical care nursing for content validity $(90 \%)$. Tool reliability was asserted using the cronbach,s coefficient alpha test. The reliability coefficient was 0.857 .

A pilot study was carried out on five students to check and ensure the clarity and applicability of the tool and the necessary modifications were done.

All students involved in the study were interviewed and were told about the aim of the study and its significance. Consent of the students for their participation was obtained after explaining the aim of the study and they were invited to assess OSCE regarding clinical competence and stressors.

\section{Ethical considerations:}

Permission was obtained from all participants of the study after explanation of the study purpose and confidentiality of data was ensured.

\section{Statistical Analysis}

Data was analyzed using the Statistical Package for Social Science (SPSS version 16). The obtained data were coded, analyzed and tabulated. Descriptive analysis was performed in this study including frequencies, percentage and Mont Carlo exact probability test.

\section{Results}

Table (1) shows description of the studied sample. It reveals that about three fifth of the studied sample $(58.8 \%)$ were aged 21years. About one fifth of them $(21.2 \%)$ were aged 22years.As regards to the sex, about two thirds of the studied sample $(67.1 \%)$ were males. Concerning the academic year the three grades were presented in the sample the second, the third and the fourth year $(36.5 \%, 31.8 \%$ and $31.8 \%$ ) respectively. 
Table (2) demonstrates Frequency distribution of students perception regarding clinical competence. It was found that about two thirds of the respondents $(63.5 \%)$ agreed or strongly agreed that they received enough information related to procedure and OSCE. However, about three fifth (59.1\%) of the present study sample agreed or strongly agreed that quality of information was quiet well. Moreover, about three thirds of the present study (58.8\%) Agreed or strongly agreed that frequency of OSCE should be 2 times per year In addition, $(83.1 \%)$ agreed or strongly agreed that will be useful to repeat the OSCE regularly.

It was found that $(83.6 \%)$ of studied sample agreed or strongly agreed that OSCE provides them with practical and useful experience. Furthermore, (71.7\%) agreed or strongly agreed that OSCE is developing confidence to conduct similar procedure on real patients. Also, it can be noted that nearly more than half of the studied sample $(55.3 \%)$ agreed or strongly agreed that OSCE scores truly reflect competence in clinical skills. In addition, $(58.8 \%)$ agreed or strongly agreed that OSCE evaluates a wide variety of clinical skills. (65.9\%) of the studied sample agreed or strongly agreed that OSCE allows students to compensate in some area. Moreover, (71\%) agreed or strongly agreed that OSCE has a positive impact on clinical learning.

Table (3) reveals frequency distribution of student's perception regarding stressors of OSCE. Regarding Level of stress $(38.8 \%)$ of the present study sample agreed or strongly agreed that it was low but, $(45.9 \%)$ of them disagreed or strongly disagreed. Concerning, the time to complete procedure, $(37.7 \%)$ of the studied sample agreed or strongly agreed that it was enough but (42.3\%) of them disagreed or strongly disagreed. And only about one third of the studied sample (31.8\%) agreed or strongly agreed that time allowed for reading instructions was enough. Furthermore, (52.9\%) disagreed or strongly disagreed that time allowed for reading instructions was enough.

More than half of the studied sample $(54.2 \%)$ agreed or strongly agreed that the atmosphere of OSCE was calm. Moreover $(57.7 \%)$ agreed or strongly agreed. About three fifth of the studied sample $(61.2 \%)$ agreed or strongly agreed that OSCE is a fair exam. About half of the studied sample (48.2\%) agreed or strongly agreed that OSCE is an easy exam. Three fifth of the studied sample $(58.8 \%)$ agreed or strongly agreed that OSCE minimizes chances of failing. (64.7\%) agreed or strongly agreed that students prefer OSCE than other formats of clinical examinations. 
Table (4) demonstrates Comparison between different academic year students' perception regarding clinical competence and stressors. It can be noted that about two thirds of $2^{\text {nd }}$ year $(61.3 \%)$ and more than half of $4^{\text {th }}$ year $(55.6 \%)$ student's perception of OSCE regarding clinical competence were moderate. While, about half of the $3^{\text {rd }}$ year $(48.1 \%)$ student's perception regarding clinical competence was high or moderate. In relation to stressors, it was found that student's perception was moderate for the 3 academic years student $(67.7 \%, 70.4 \%$ and $63.0 \%$ ) respectively. In addition there is no significant difference between them for both clinical competence and stressors $\mathrm{p}=0.538$ and 0.394 respectively.

\section{Discussion}

Nursing educators became oriented with OSCE in the last decade ${ }^{(1)}$. The aim of this study was to assess Objective Structured Clinical Examination's regarding clinical competence and stressors among the undergraduate student nursing.

In relation to age of students it was found that the majority of students' age was 21 years old and the majority was male. Because, male nurses are more willing in our faculty to participate in researches and they are eager to promote their career and faculty more than female nurses. Moreover, the sample obtained from second academic year was more than those obtained from other academic years because the total number of second year more than those of the two other academic year.

In relation to the student's perception of OSCE regarding clinical competence. About two thirds of the respondents agreed or strongly agreed that they received enough information to procedure and OSCE. On the other hand, about one fifth of the present study sample whether disagreed or strongly disagreed (table 2). It is congruent with a study performed to assess the perceptions of student nurses regarding OSCE; they reported that they had received sufficient information from their lecturers in preparation for their OSCE examinations and one fifth of the studied sample were of opinion that they had not received enough information ${ }^{(2)}$. Receiving enough information is essential for procedures and OSCE or the students will be confused and stressed in the examination. Moreover, it may affect their clinical competence. Knowledge is a master key for clinical competence and it plays a crucial role for clinical competence.

Three fifth of the present study sample agreed or strongly agreed that Quality of information was high. This may be because 
they found it highly informative and useful. More than half of the present sample Agreed or strongly agreed that once for year frequency of OSCE is not enough. In addition, the majority of the studied sample agreed or strongly agreed that OSCE sessions should be repeated more regularly (table 2). This could be because they perceived the educational value of OSCE. A similar finding was reported in a previous study performed to assess students and staff members' perspective regarding OSCE. They found that most of the students think the OSCE should be repeated more regularly (3 to 4 times per year) ${ }^{(3)}$

More than half of the studied sample agreed or strongly agreed that OSCE scores truly reflect competence in clinical skills. In a previous study performed in Hertfordshire, UK, assessing nursing students and lecturers perspective regarding OSCE. It was found that the majority of studied sample agreed that OSCE helped in developing their confidence. In addition, OSCE allows student to compensate in some area. Similarly, OSCEs are regarded by most students as comprehensive-covering a range of knowledge and clinical competences and useful practical experience $^{(15)}$. This could be because OSCE has been considered as an acceptable method for assessment for clinical skills in nursing students.

The majority of studied sample agreed that OSCE helped in developing confidence. El darir and Abd el Hamid in 2013, comparing OSCE and traditional clinical assessment, found that the highest rate of satisfaction and clinical competence belonged to OSCE methods of evaluation as the students reported that OSCE enhancing teaching level, relate theory to practice, increased decision making ability, enhanced methods of evaluation and makes exam well developed, than the traditional $\operatorname{method}^{(16)}$.

Psychological condition of learner is very important during clinical education. Relaxed student can be easily educated than tensed one. Concerning students' perception regarding stressors associated with OSCE. Getting feedback from the students will help examiners to solve the unresolved stress associated with OSCE experience. Moreover, spending enough time in OSCE decreases stress associated. More than half of the studied sample agreed or strongly agreed that the atmosphere of OSCE was calm (table 3). As presence of clear instructions in the beginning of OSCE experience in addition to enough organization lead to abundance of calm environment. This is congruent with a study performed in Cairo, Egypt 
$(2013)^{(16)}$ the respondents agreed that the environment of the OSCE was calm.

Byrne and Smyth (2008) concluded that students already exposed to an OSCE described feeling less anxious and better prepared for their subsequent clinical placements. They found similar experiences among the students interviewed. The OSCE had caused feelings of anxiety, yet students felt that the assessment was ultimately beneficial to them ${ }^{(17)}$.

In a literature review by Rushforth (2007), in which students reported the OSCE process as stressful, maybe causing a detrimental effect on their performance and yet overall they valued the OSCE as a worthwhile experience. However, the findings of this and other studies suggest that anxiety can have beneficial effects in adapting people to stressful situations ${ }^{(18)}$. In a study performed in Saudi Arabia on family medicine undergraduate students perception of OSCE (2012), found it to be very stressful $^{(19)}$.

Concerning, the time to complete procedure, near half of the studied sample found that there was no enough time to complete the procedure (table 3). It was found in a previous study that the time allocated for each station was adequate ${ }^{(20)}$. Abdulla found that as a response on a question on OSCE stations is the duration of the station and whether it is sufficient to achieve the task or not, so the respondents stated that the time allocated for each station was adequate ${ }^{(13)}$. Katwa-Mukwato in (2013) reported that OSCEs are also time consuming in both preparations and actual administration ${ }^{(21)}$.

More than half of the studied sample agreed that OSCE was fair enough. Omari and Shawagfa (2004) found in a study performed in Jordon Medical School. The study was performed to evaluate use of objective structured clinical examination (OSCE) in Jordanian medical school. They found that the majority of studied sample agreed that it was fair and comprehensive exam $^{(20)}$. This could be logic as OSCE is an exceptional learning experience which offers reflection.

About half of the studied sample agreed or strongly agreed that OSCE is an easy exam. This could be because OSCE is an experience that is considered fair and unbiased, cover a wide range of knowledge and comprehensive, and provide opportunities to leaning. The present study findings are compatible with what was found in a previous that OSCE is an easy exam and they learned a lot through $\operatorname{OSCE}^{(21)}$.

More than half of the studied sample agreed or strongly agreed that OSCE minimizes chances of failing and they were 
prepared differently for OSCE than for other clinical examinations. This finding is compatible with the findings of Ali et al in a study performed in Faculty of Nursing, Sohag University, Egypt, found that OSCE has been fair assessment tool, comprehensive and minimized the chance of failing, and highlighted areas of student's weakness. However, some students felt that OSCE was very stressful and half of student expressed concerns about inadequacy of time. As well, the OSCE provided opportunities to learning, reflected those which were taught, and nearly half of them reported that the stations were organized and of logical sequence and appropriate. More than half of the student felt that, the exam score provide true measure clinical skill believed that the score was standardized ${ }^{(22)}$.

As regards to the comparison between student's perceptions of different academic years (table 4). It was found that student's perception did not change after one year and there was no difference between students perception. It may be related to the department staff did not promote or changed their strategy during OSCE. So, OSCE should be tailored according to students' needs and achievements.

\section{Conclusion}

Evaluation of OSCE experience by students helps defines some of deficiencies or obstacles in the conduction of this examination. Moreover, it helps in the assessment of their clinical competence. It can be concluded that The OSCE possesses a number of intrinsic advantages in relation to clinical competence. It develops students' self confidence because; it is a comprehensive exam covering a wide range of knowledge, clinical skills and useful practical experience which promotes students' clinical competence. But, although most of students agreed that they have received enough time during preparation of OSCEs. Moreover, it is fair exam and have calm atmosphere. It can be considered time consuming in preparations with time limitation while implementation and the majority of students considered time limited as one of the important factor in producing stress in OSCE method and subsequently it decreases their psychological condition.

\section{Recommendations}

Based on the findings of the current results, the following recommendations are suggested:

1. Determine time needed for each procedure and accommodate 
OSCE Regarding Clinical Competence and Stressors

OSCE according its one. So, time should not be fixed for each procedure or specific modification should be done if fixed time is needed.
2. Increase frequencies of OSCE through open lab hour with the same structure and giving immediate feedback for students to increase their self confidence during any following exams. 
OSCE Regarding Clinical Competence and Stressors

Table (1): Description of the studied sample.

\begin{tabular}{||c|c|c|}
\hline Characteristics & No & \% \\
\hline - 20 & & \\
\hline - 21 & 7 & 8.2 \\
\hline - 22 & 50 & 58.8 \\
\hline - 23 & 18 & 21.2 \\
\hline - Mex & 10 & 11.8 \\
\hline - Female & 57 & 67.1 \\
\hline Academic year & 28 & 32.9 \\
\hline - $2^{\text {nd }}$ year & 31 & 36.5 \\
\hline - $3^{\text {rd }}$ year & 27 & 31.8 \\
\hline - $4^{\text {th }}$ year & 27 & 31.8 \\
\hline
\end{tabular}


OSCE Regarding Clinical Competence and Stressors

Table (2): Frequency distribution of student's perception regarding clinical competence.

\begin{tabular}{|c|c|c|c|c|c|}
\hline \multirow{2}{*}{ Clinical competence } & $\begin{array}{l}\text { Strongly } \\
\text { disagree }\end{array}$ & Disagree & $\begin{array}{l}\text { Not } \\
\text { sure }\end{array}$ & Agree & $\begin{array}{l}\text { Strongly } \\
\text { agree }\end{array}$ \\
\hline & $\begin{array}{c}\text { No } \\
\%\end{array}$ & $\begin{array}{c}\text { No } \\
\%\end{array}$ & $\begin{array}{c}\text { No } \\
\%\end{array}$ & $\begin{array}{c}\text { No } \\
\%\end{array}$ & $\begin{array}{c}\text { No } \\
\%\end{array}$ \\
\hline $\begin{array}{l}\text { 1- Receiving enough } \\
\text { information }\end{array}$ & $\begin{array}{c}2 \\
2.4\end{array}$ & $\begin{array}{c}16 \\
18.8\end{array}$ & $\begin{array}{c}13 \\
15.3\end{array}$ & $\begin{array}{c}45 \\
52.9\end{array}$ & $\begin{array}{c}9 \\
10.6\end{array}$ \\
\hline $\begin{array}{l}\text { 4-Receiving high quality of } \\
\text { information }\end{array}$ & $\begin{array}{c}2 \\
2.4\end{array}$ & $\begin{array}{l}10 \\
12\end{array}$ & $\begin{array}{c}22 \\
26.5\end{array}$ & $\begin{array}{c}33 \\
39.8\end{array}$ & $\begin{array}{c}16 \\
19.3\end{array}$ \\
\hline 2- Frequency of OSCE & $\begin{array}{c}3 \\
3.5\end{array}$ & $\begin{array}{c}13 \\
15.3\end{array}$ & $\begin{array}{c}19 \\
22.4\end{array}$ & $\begin{array}{c}35 \\
41.2\end{array}$ & $\begin{array}{c}15 \\
17.6\end{array}$ \\
\hline $\begin{array}{l}\text { 3- Regular repetition OSCE } \\
\text { sessions }\end{array}$ & $\begin{array}{c}1 \\
1.2\end{array}$ & $\begin{array}{c}3 \\
3.6\end{array}$ & $\begin{array}{c}10 \\
12.0\end{array}$ & $\begin{array}{c}38 \\
45.8\end{array}$ & $\begin{array}{c}31 \\
37.3\end{array}$ \\
\hline $\begin{array}{l}\text { 5-Providing practical and } \\
\text { useful experience }\end{array}$ & $\begin{array}{c}1 \\
1.2\end{array}$ & $\begin{array}{c}7 \\
8.2\end{array}$ & $\begin{array}{c}6 \\
7.1\end{array}$ & $\begin{array}{c}35 \\
41.2\end{array}$ & $\begin{array}{c}36 \\
42.4\end{array}$ \\
\hline $\begin{array}{l}\text { 6-Developing confidence to } \\
\text { conduct similar procedure } \\
\text { on real patient }\end{array}$ & $\begin{array}{c}2 \\
2.4\end{array}$ & $\begin{array}{c}8 \\
9.4\end{array}$ & $\begin{array}{c}14 \\
16.5\end{array}$ & $\begin{array}{c}41 \\
48.2\end{array}$ & $\begin{array}{c}20 \\
23.5\end{array}$ \\
\hline $\begin{array}{l}\text { 7-Reflecting competence in } \\
\text { clinical skills }\end{array}$ & $\begin{array}{c}7 \\
8.2\end{array}$ & $\begin{array}{c}10 \\
11.8\end{array}$ & $\begin{array}{c}21 \\
24.7\end{array}$ & $\begin{array}{c}36 \\
42.4\end{array}$ & $\begin{array}{c}11 \\
12.9\end{array}$ \\
\hline $\begin{array}{l}\text { 8- Evaluating a wide } \\
\text { variety of clinical skills }\end{array}$ & $\begin{array}{c}5 \\
5.9\end{array}$ & $\begin{array}{c}11 \\
12.9\end{array}$ & $\begin{array}{c}19 \\
22.4\end{array}$ & $\begin{array}{c}33 \\
38.8\end{array}$ & $\begin{array}{l}17 \\
20\end{array}$ \\
\hline $\begin{array}{l}\text { 9- Allowing student to } \\
\text { compensate in some area }\end{array}$ & $\begin{array}{c}4 \\
4.7\end{array}$ & $\begin{array}{c}8 \\
9.4\end{array}$ & $\begin{array}{l}17 \\
20\end{array}$ & $\begin{array}{c}38 \\
44.7\end{array}$ & $\begin{array}{c}18 \\
21.2\end{array}$ \\
\hline $\begin{array}{l}\text { 10-Having a positive impact } \\
\text { on clinical learning }\end{array}$ & $\begin{array}{c}2 \\
2.4\end{array}$ & $\begin{array}{c}4 \\
4.7\end{array}$ & $\begin{array}{c}11 \\
12.9\end{array}$ & $\begin{array}{c}43 \\
50.6\end{array}$ & $\begin{array}{c}25 \\
29.4\end{array}$ \\
\hline Overall $($ Mean \pm SD) & & & $24.2 \pm$ & & \\
\hline
\end{tabular}


OSCE Regarding Clinical Competence and Stressors

Table (3): Frequency distribution of student's perception regarding stressors of OSCE.

\begin{tabular}{|c|c|c|c|c|c|}
\hline & $\begin{array}{l}\text { Strongly } \\
\text { disagree }\end{array}$ & disagree & Not sure & Agree & $\begin{array}{l}\text { Strongly } \\
\text { agree }\end{array}$ \\
\hline & $\begin{array}{l}\text { No } \\
\%\end{array}$ & $\begin{array}{c}\text { No } \\
\%\end{array}$ & $\begin{array}{l}\text { No } \\
\%\end{array}$ & $\begin{array}{l}\text { No } \\
\%\end{array}$ & $\begin{array}{l}\text { No } \\
\%\end{array}$ \\
\hline 1- Calm atmosphere & $\begin{array}{c}7 \\
8.2\end{array}$ & $\begin{array}{c}16 \\
18.8\end{array}$ & $\begin{array}{c}16 \\
18.8\end{array}$ & $\begin{array}{c}27 \\
31.8\end{array}$ & $\begin{array}{c}19 \\
22.4\end{array}$ \\
\hline 2- Low stress level & $\begin{array}{c}12 \\
14.1\end{array}$ & $\begin{array}{c}27 \\
31.8\end{array}$ & $\begin{array}{c}13 \\
15.3\end{array}$ & $\begin{array}{c}26 \\
30.6\end{array}$ & $\begin{array}{c}7 \\
8.2\end{array}$ \\
\hline $\begin{array}{l}\text { 3-OSCE is less stressful } \\
\text { than other clinical exams }\end{array}$ & $\begin{array}{c}5 \\
5.9\end{array}$ & $\begin{array}{c}21 \\
24.7\end{array}$ & $\begin{array}{c}19 \\
22.4\end{array}$ & $\begin{array}{c}21 \\
24.7\end{array}$ & $\begin{array}{c}19 \\
22.4\end{array}$ \\
\hline $\begin{array}{l}\text { 4- Enough time to } \\
\text { complete procedure }\end{array}$ & $\begin{array}{c}11 \\
12.9\end{array}$ & $\begin{array}{c}25 \\
29.4\end{array}$ & $\begin{array}{l}17 \\
20\end{array}$ & $\begin{array}{c}19 \\
22.4\end{array}$ & $\begin{array}{c}13 \\
15.3\end{array}$ \\
\hline $\begin{array}{l}\text { 5- Enough time for } \\
\text { reading instructions }\end{array}$ & $\begin{array}{c}13 \\
15.3\end{array}$ & $\begin{array}{c}32 \\
37.6\end{array}$ & $\begin{array}{c}13 \\
15.3\end{array}$ & $\begin{array}{c}21 \\
24.7\end{array}$ & $\begin{array}{c}6 \\
7.1\end{array}$ \\
\hline $\begin{array}{l}\text { 6- standardization of } \\
\text { OSCE exam }\end{array}$ & $\begin{array}{c}5 \\
5.9\end{array}$ & $\begin{array}{c}12 \\
14.1\end{array}$ & $\begin{array}{c}19 \\
22.4\end{array}$ & $\begin{array}{c}27 \\
31.8\end{array}$ & $\begin{array}{c}22 \\
25.9\end{array}$ \\
\hline $\begin{array}{l}\text { 7- fairness of OSCE } \\
\text { exam }\end{array}$ & $\begin{array}{c}7 \\
8.2\end{array}$ & $\begin{array}{c}11 \\
12.9\end{array}$ & $\begin{array}{c}15 \\
17.6\end{array}$ & $\begin{array}{c}26 \\
30.6\end{array}$ & $\begin{array}{c}26 \\
30.6\end{array}$ \\
\hline 8-OSCE is easy exam & $\begin{array}{c}7 \\
8.2\end{array}$ & $\begin{array}{c}14 \\
16.5\end{array}$ & $\begin{array}{c}23 \\
27.1\end{array}$ & $\begin{array}{c}25 \\
29.4\end{array}$ & $\begin{array}{c}16 \\
18.8\end{array}$ \\
\hline $\begin{array}{l}\text { 9-OSCE is preferable to } \\
\text { other formats of clinical } \\
\text { examination }\end{array}$ & $\begin{array}{c}3 \\
3.5\end{array}$ & $\begin{array}{c}12 \\
14.1\end{array}$ & $\begin{array}{c}15 \\
17.6\end{array}$ & $\begin{array}{l}34 \\
40\end{array}$ & $\begin{array}{c}21 \\
24.7\end{array}$ \\
\hline $\begin{array}{l}\text { 10- Minimizing chances } \\
\text { of failing }\end{array}$ & $\begin{array}{c}1 \\
1.2\end{array}$ & $\begin{array}{c}8 \\
9.4\end{array}$ & $\begin{array}{c}26 \\
30.6\end{array}$ & $\begin{array}{l}34 \\
40\end{array}$ & $\begin{array}{c}16 \\
18.8\end{array}$ \\
\hline Overall $($ Mean \pm SD) & \multicolumn{5}{|c|}{$17.8 \pm 4.8$} \\
\hline
\end{tabular}


Table (4): Comparison between different academic years students' perception regarding clinical competence and stressors.

\begin{tabular}{|c|c|c|c|c|c|c|c|c|c|c|}
\hline \multirow{3}{*}{$\begin{array}{l}\text { Student } \\
\text { perception } \\
\text { regarding: }\end{array}$} & \multicolumn{3}{|c|}{$2^{\text {nd }}$ year } & \multicolumn{3}{|c|}{$3^{\text {rd }}$ year } & \multicolumn{3}{|c|}{$4^{\text {th }}$ year } & \multirow[t]{3}{*}{ MCP } \\
\hline & Low & Moderate & High & Low & Moderate & High & Low & $\begin{array}{l}\text { Moder } \\
\text { ate }\end{array}$ & High & \\
\hline & $\begin{array}{c}\text { No } \\
\%\end{array}$ & $\begin{array}{l}\text { No } \\
\%\end{array}$ & $\begin{array}{l}\text { No } \\
\%\end{array}$ & $\begin{array}{c}\text { No } \\
\%\end{array}$ & $\begin{array}{l}\text { No } \\
\%\end{array}$ & $\begin{array}{l}\text { No } \\
\%\end{array}$ & $\begin{array}{l}\text { No } \\
\%\end{array}$ & $\begin{array}{c}\text { No } \\
\%\end{array}$ & $\begin{array}{l}\text { No } \\
\%\end{array}$ & \\
\hline $\begin{array}{l}\text { 1- Clinical } \\
\text { competence }\end{array}$ & $\begin{array}{c}1 \\
3.2 \\
\end{array}$ & $\begin{array}{c}19 \\
61.3 \\
\end{array}$ & $\begin{array}{c}11 \\
35.5 \\
\end{array}$ & $\begin{array}{c}1 \\
3.8 \\
\end{array}$ & $\begin{array}{c}13 \\
48.1 \\
\end{array}$ & $\begin{array}{c}13 \\
48.1 \\
\end{array}$ & $\begin{array}{c}2 \\
7.4\end{array}$ & $\begin{array}{c}15 \\
55.6\end{array}$ & $\begin{array}{c}10 \\
37.0\end{array}$ & 0.538 \\
\hline 2-Stressors & $\begin{array}{c}8 \\
25.8\end{array}$ & $\begin{array}{c}21 \\
67.7\end{array}$ & $\begin{array}{c}2 \\
6.5\end{array}$ & $\begin{array}{c}5 \\
18.5\end{array}$ & $\begin{array}{c}19 \\
70.4\end{array}$ & $\begin{array}{c}3 \\
11.1\end{array}$ & $\begin{array}{c}6 \\
22.2\end{array}$ & $\begin{array}{c}17 \\
63.0\end{array}$ & $\begin{array}{c}4 \\
14.8\end{array}$ & 0.394 \\
\hline
\end{tabular}

MCP: P value based on Mont Carlo exact probability. $* \mathrm{P}<0.05$ (significant) 


\section{References}

1. Chehrzad MM, Shafie pour SZ, mirzaei M, Kazem Nejad E. Comparison between two methods: Objective structured clinical evaluation (OSCE) and traditional on nursing students, satisfaction. Journal of Medical Faculty Guilan University of medical Sciences.2004; 13(50): 8-13.

2. Alsenany S, Al Saif A. Developing skills in managing Objective Structured Clinical Examinations (OSCE). Life Science journal. (2012); 9(3): 597-602.

3. Gamboa-Salcedo, T., Martinez-Viniegra, N., Pena-Alonso, Y.R., Pacheco-Rios, A., Garcia- Duran, R. \& SanchezMedina, J. 'Objective Structured Clinical Examination as an instrument for evaluation of clinical competence in pediatrics. (2011); 68(3): 169-176.

4. Walsh M, Bailey H, Koren I. Objective Structure Evaluation of Clinical Competence: An Integrative Review. Journal of Advanced Nursing 2009; 65(8):1584-1595.

5. El-Nemer, A. \&Kandeel, N., 2009, 'Using OSCE as an assessment tool for clinical skills: Nursing students' feedback', Australian Journal of Basic and Applied Sciences 3(3), 2465-2472.

6. Maryam B, Malihe S, Maryam S. The Comparison of Stressors in the
Assessment of Basic Clinical Skills with Traditional Method and OSCE in nursing Students. 2012; 9(4): 1748-1749.

7. Rushforth H E. Objective Structured Clinical Examination: Review of Literature and Implication for Nursing Education. Nurse education today 2007; 27:481-490.

8. Watson R, Stimpson A, Topping A, Porock, D. Integrative Literature Reviews and Meta- Analyses, Clinical competence assessment in nursing: a systematic review of the literature. Journal of Advanced Nursing. (2002) Volume 39, (5): 421.

9. Casey PM, Goepfert AR, Espey EL, Hammoud MM, Kaczmarczyk JM, Katz NT, N. The Objective Structured Clinical Examination. American Journal Obstetric Gynecology; (2009); 200(1): 25-34.

10. Ahmad, C., N. Ahmad \& Abu Baker R., Assessing Nursing Clinical Skills Performance Using Objective Structured ClinicalExamination (OSCE) for Open Distance Learning Students in Open University Malaysia(2009). 8(5)12-13.

11. Selim A, Ramadan F, El-Gueneidy M, Gaafer M. Using Objective Structured Clinical Examination (OSCE) in undergraduate psychiatric nursing 
OSCE Regarding Clinical Competence and Stressors

education: Is it reliable and valid? Nurse Education Today (2012) (32) 283-288.

12. Alinier, G. Nursing students 'and lecturers' perspectives of objective structured clinical examination incorporating simulation. Nurse Education Today., 2003, 23(6): 419-426.

13. Abdulla M. Student's perception of objective structured clinical examination (OSCE) in surgery at Basrah College of medicine. Bas J Surg2012, September, 18:21-5.

14. Bagheri M, Forotgheh M, Fallah M. The Comparison of Stressors in the Assessment of Basic Clinical Skills with Traditional Method and OSCE in nursing Students. Life Science Journal 2012; 9(4):1748-52.

15. Alinier G. Nursing students' and lecturers' perspectives of OSCE, incorporating simulation. BHF Project. Department of Nursing \& Paramedic Sciences ,University of Hertfordshire. Available at: http://uhra.herts.ac.uk/bitstream/handle/2 299/393/103693.pdf?sequence $=1$

16. Eldarir S, Abd el Hamid N. Objective Structured Clinical Evaluation (OSCE) versus Traditional Clinical Students Achievement at Maternity Nursing: A Comparative Approach. Journal of
Dental and Medical Sciences2013, 4(3):63-8.

17. Byrne, E. and Smyth, S. (2008) Lecturers' experiences and perspectives of using an objective structured clinical examination. Nurse Education in Practice2008; 8: 283-9.

18. Rushforth, H.E. Objective structured clinical examination (OSCE): Review ofliterature and implications for nursing education. Nurse Education Today (2007), 27: 481-90.

19. Raheel H, Naeem G. Assessing the Objective Structured Clinical Examination: Saudi family medicine undergraduate medical students' perceptions of the tool.J Pak Med Assoc.

20. Omari A, Shawagfa M. New experience with objective structured clinical examination in Jordan. New experience with objective structured clinical examination in Jordan. Available at: http://www.biomedcentral.com/1472$\underline{6920 / 4 / 22}$

21. Katowa-Mukwato P, Mwape L, Kabinga-Makukula M, Mweemba $\mathrm{P}$, Maimbolwa M. Implementation of Objective Structured Clinical Examination for Assessing Nursing Students' Clinical Competencies: Lessons and Implications. Scientific 
OSCE Regarding Clinical Competence and Stressors

Research 2013, 4(10A): 48-53. students' perspective. Journal of

Available $\quad$ at: $\quad$ Environmental Studies2012, 8: 59-69.

http://www.scirp.org/journal/ce

22. Ali GA, Mehdi AY, Ali HA. Objective

Structured Clinical Examination

(OSCE). Assessment Tool for Clinical

Skills in Sohag University: Nursing 